\title{
ASPECTOS FLORÍSTICOS E FITOSSOCIOLÓGICOS DA RESERVA CAPÃO DE TUPANCIRETÃ, TUPANCIRETÃ, RS, BRASIL ${ }^{1}$

\author{
FLORISTIC AND PHYTOSSOCIOLOGICAL ASPECTS IN CAPÃO DE TUPANCIRETÃ
} RESERVATION, TUPANCIRETÃ, RS, BRASIL
}

\author{
Suzana Ferreira da Rosa ${ }^{2}$ Solon Jonas Longhi ${ }^{3}$ Marcos Paulo Ludwig ${ }^{4}$ \\ RESUMO
}

Este trabalho foi realizado na Reserva Capão de Tupanciretã, município de Tupanciretã (RS), em uma área com 8 hectares pertencente à Fundação de Pesquisa Agropecuária do Rio Grande do Sul (FEPAGRO). O objetivo do trabalho foi avaliar a composição florística e estrutura fitossociológica da floresta. Utilizaram-se dez parcelas de tamanho 10 x $20 \mathrm{~m}$ distribuídas sistematicamente na área. Nessas parcelas, foram medidos e identificados todos os indivíduos com DAP maior ou igual a $5 \mathrm{~cm}$. Dentro das parcelas principais, alocaram-se subunidades de 5 x $5 \mathrm{~m}$ para avaliar o componente arbustivo (DAP entre $1 \mathrm{e}$ $5 \mathrm{~cm}$ ) e de $2 \times 2 \mathrm{~m}$ para a regeneração natural (DAP menor que $1 \mathrm{~cm}$ e altura superior a $30 \mathrm{~cm}$ ). Os resultados foram analisados usando o programa FITOANALISE, calculando-se os parâmetros fitossociológicos tradicionais de densidade, dominância, freqüência, valor de importância, valor de cobertura e índice de diversidade. As espécies com maior representatividade no componente arbóreo da floresta foram Camboatá-vermelho (Cupania vernalis Cambess.) e o Branquilho (Sebastiania commersoniana (Baill.) L. B. Sm. \& Downs). No componente arbustivo e na regeneração, as espécies que apresentaram o maior número de indivíduos foram Camboatá-vermelho (Cupania vernalis Cambess.), Primavera (Brunfelsia australis Benth.), Chal-chal (Allophylus edulis (A. St.-Hil, Cambess. \& A. Juss.) e Canela-amarela (Nectandra lanceolata Nees).

Palavras-chave: fitossociologia; espécies arbóreas; diversidade florística.

\section{ABSTRACT}

This work was accomplished in Capão de Tupanciretã Reservation, in the city of Tupanciretã, Rio Grande do Sul, in an area with 8 hectares, belonging to the Fundation of Agropecuary Research of Rio Grande do Sul. The objective of the paper was to evaluate the floristic composition and the phytosociological structure of the forest. Ten samplings of $10 \times 20 \mathrm{~m}$ were distributed systematically in the area. In the sampling module, every individual with DAP major or equal to $5 \mathrm{~cm}$ was measured and identified. In the sampling, a split sample of $5 \times 5 \mathrm{~m}$ was marked to evaluate the bush component (DAP between 1 and $5 \mathrm{~cm}$ ) and one of 2 x 2 was used to evaluate the regeneration (DAP smaller than $1 \mathrm{~cm}$ and higher than $30 \mathrm{~cm}$ ). The results were analyzed considering the FITOANALISE program, it was calculated the traditional phytosociological parameters like density, dominancy, frequency, importance of the value, coverage of the value and index of the diversity. The most present species in the tree component of the forest were Cupania vernalis Cambess. and Sebastiania commersoniana (Baill.) L. B. Sm. \& Downs. The biggest number of species in the bush component and in regeneration were Cupania vernalis Cambess., Brunfelsia australis Benth., Allophylus edulis (A. St.-Hil. Cambess. \& A. Juss.) Radlk. and Nectandra lanceolata Nees.

Keywords: phytosociology; foresty species; floristic diversity.

\section{INTRODUÇÃO}

A região do Planalto Médio do Rio Grande do Sul apresenta terreno relativamente ondulado formando coxilhas. A vegetação é predominantemente formada por campos onde as matas se concentram nas

1. Trabalho desenvolvido com o apoio da Fundação Estadual de Pesquisa Agropecuária (Fepagro) de Tupanciretã e EMATER, Tupanciretã (RS).

2. Acadêmica do Curso de Engenheira Florestal, Centro de Ciências Rurais, Universidade Federal de Santa Maria, Av. Roraima, 1000, CEP 97105-900, Santa Maria (RS).suzanafdr@yahoo.com.br

3. Engenheiro Florestal, Dr., Professor Titular do Departamento de Ciências Florestais, Centro de Ciências Rurais, Universidade Federal de Santa Maria, Av. Roraima, 1000, CEP 97105-900, Santa Maria (RS). longhi.solon@gmail.com

4. Engenheiro Agrônomo, Acadêmico do Programa de Pós-Graduação em Ciência e Tecnologia de Sementes, Universidade Federal de Pelotas, Rua Barão de Santa Tecla, 1180, Apartamento 13, Bairro Centro, CEP 96010-000, Pelotas (RS). plmarcos1@yahoo.com.br

Recebido para publicação em 17/04/2007 e aceito em 20/12/2007. 
margens dos cursos de água, formando "galerias" ou em pequenas manchas isoladas em formato arredondado, formando “capões”, com vegetação densa e fechada (RAMBO, 1956).

A preservação e o manejo dos pequenos fragmentos florestais são, muitas vezes, enfocados de forma secundária no Brasil. Com isso, pode-se estar menosprezando a importância das pequenas reservas que, em muitos casos, são a maior parte dos remanescentes de florestas naturais, normalmente pouco amparadas pelas políticas conservacionistas, mas de grande importância para o planejamento da recuperação e manejo de áreas degradadas (PIRAPITINGA, 2004).

Estudos florísticos e fitossociológicos das florestas são essenciais para a conservação da diversidade pois fornecem o conhecimento do estado atual dos fragmentos e subsídios para planos de recuperação destes. Além disso, a obtenção e padronização dos atributos de diferentes ambientes florísticos e fisionômicos são atividades básicas para a conservação e preservação, possibilitando a proposição de modelos mais adequados de manejo de florestas (OLIVEIRA \& AMARAL, 2004). Esses estudos são básicos para o conhecimento das relações entre comunidades de plantas e fatores ambientais ao longo das variações de latitude, longitude, altitude, classes de solos, gradientes de fertilidade e de umidade dos solos (SILVA JUNIOR, 2005).

A análise da estrutura horizontal das comunidades vegetais utiliza parâmetros de densidade, dominância, valor de importância e valor de cobertura. Segundo Longhi (1997), esses parâmetros revelam informações sobre a distribuição espacial das populações e sua participação no ecossistema.

A densidade representa o número de indivíduos de uma espécie por unidade de área ou de volume, e a dominância expressa a proporção de tamanho, volume ou cobertura de cada espécie em relação ao espaço da fitocenose (MARTINS, 1991). A freqüência indica a porcentagem de ocorrência de uma espécie em um número de áreas de igual tamanho dentro de uma comunidade (SOUZA, 1973 apud LONGHI, 1997). O valor de importância representa a combinação dos valores fitossociológicos relativos a cada espécie, e o valor de cobertura, a soma dos índices relativos de densidade e dominância (MATTEUCCI e COLMA, 1982 apud HACK et al., 2005).

Além desses índices, a caracterização de uma comunidade vegetal utiliza valores de diversidade. Araújo (2002) considerou que uma elevada diversidade ocorre quando muitas espécies se apresentam igualmente abundantes em uma comunidade. Dentre os índices de diversidade, a autora utilizou o índice de Shannon, que se baseia no número e uniformidade das espécies.

Também, é importante a análise da estrutura vertical, que revela o estágio de desenvolvimento da floresta pela ocupação das espécies na sua estratificação, pois não é importante apenas a existência de uma espécie em um fragmento florestal, mas também suas condições de ocupação.

A regeneração das espécies vegetais é um processo natural em que cada espécie desenvolve características próprias, em perfeita sintonia com as condições ambientais, permitindo assim, por meio da dinâmica natural, a perpetuação de todas as espécies vegetais através do tempo (CAMPOS e LANDGRAF, 2001).

A região em estudo apresenta grande interesse econômico de suas áreas para a atividade agrícola, a qual, por sua vez, pode descaracterizar a vegetação original. Nesse sentido, estudos sobre a diversidade florística na região tornam-se importante para o conhecimento da dinâmica dos fragmentos florestais existentes e, dessa forma, contribuir para a manutenção de sua diversidade.

Dessa forma, o objetivo do presente trabalho foi avaliar a composição florística, a estrutura fitossociológica e a regeneração natural na Reserva Capão de Tupanciretã, localizada no município de Tupanciretã, RS.

\section{MATERIAL E MÉTODO}

\section{Caracterização da área de estudo}

O trabalho foi realizado na Reserva Ecológica Capão de Tupanciretã, pertencente à Fundação Estadual de Pesquisa Agropecuária (FEPAGRO), no município de Tupanciretã, RS. Essa área está situada sob as coordenadas geográficas de $29^{\circ} 04^{\prime}$ 03,71” de latitude sul e $53^{\circ} 50^{\prime} 45,12^{\prime}$ ' de longitude oeste, a uma altitude de $431 \mathrm{~m}$ (CALIL, 2003). 
O clima da região segundo a classificação de Köppen é do tipo Cfa - subtropical úmido, com chuvas distribuídas em todos os meses do ano e temperatura do mês mais quente superior a $22^{\circ} \mathrm{C}$ e a do mês mais frio, entre -3 e $18^{\circ} \mathrm{C}$ (MORENO, 1961).

O município de Tupanciretã está localizado na região fisiográfica do Planalto Médio, limitada ao norte pela região do Alto Uruguai, ao sul pela Depressão Central e a leste pela Encosta Superior do Nordeste. A maior parte da região é formada geologicamente por basalto e pertence à Bacia Hidrográfica do Alto Jacui (RIO GRANDE DO SUL, 2002).

O solo é classificado como Argissolo Vermelho - Amarelo Distrófico Típico (STRECK et al., 1999).

\section{Metodologia utilizada}

O levantamento da vegetação com DAP maior ou igual a $5 \mathrm{~cm}$ foi realizado utilizando-se dez parcelas retangulares, com $10 \mathrm{~m}$ de largura e $20 \mathrm{~m}$ de comprimento $\left(200 \mathrm{~m}^{2}\right)$, distribuídas sistematicamente na área a uma distância de $100 \mathrm{~m}$ entre parcelas, perfazendo uma intensidade amostral de 2,5\%.

Em cada parcela, foram amostrados os indivíduos arbóreos e arbustivos, que apresentaram diâmetro a altura do peito (DAP) maior ou igual a $5 \mathrm{~cm}$. A maioria dos indivíduos foram identificados in loco, registrando o nome vulgar. Para as espécies não-identificadas, coletou-se o material botânico que foi encaminhado ao Herbário do Departamento de Ciência Florestal da UFSM (HDCF) para a correta identificação. Foi adotado o Sistema de Classificação APG II (2003). Também registraram-se o diâmetro a altura do peito com o auxílio de suta dendrométrica, a altura total com o hipsômetro Blume-Leiss, e a posição sociológica (posição ocupada pelas árvores) em três estratos: superior, médio e inferior.

Para a identificação do componente arbustivo e da regeneração natural, foram alocadas subparcelas de tamanhos menores localizadas na extremidade final de cada parcela principal. Para a vegetação arbustiva utilizaram-se subparcelas de tamanho $5 \mathrm{~m}$ x $5 \mathrm{~m}\left(25 \mathrm{~m}^{2}\right)$, identificando e quantificado todos os indivíduos

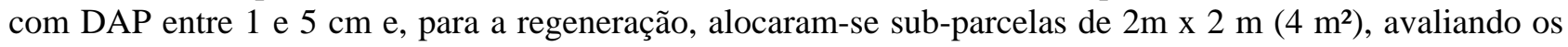
indivíduos com DAP menor que $1 \mathrm{~cm}$ e altura igual ou maior que $30 \mathrm{~cm}$.

Os resultados foram analisados pelo do programa estatístico Fitoanálise (CARVALHO JÚNIOR et al., 1999), calculando-se os parâmetros fitossociológicos tradicionais: densidade, dominância, freqüência, valor de importância, valor de cobertura, índice de diversidade.

\section{RESULTADOS E DISCUSSÃO}

Verificou-se que o número de parcelas utilizadas no trabalho foram suficientes para representar a composição florística da área estudada, sendo possível observar tendência à estabilização na curva espécieárea (Figura 1). Observou-se que, até $800 \mathrm{~m}^{2}$ de amostragem, houve um grande acréscimo no número de espécies amostradas, e, partindo daí, o aumento no número de espécies foi gradativo até uma área de 1.800 $\mathrm{m}^{2}$ onde houve uma estabilização na curva espécie-área, indicando que a intensidade amostral de $2,5 \%$ foi suficiente para representar a população existente. 


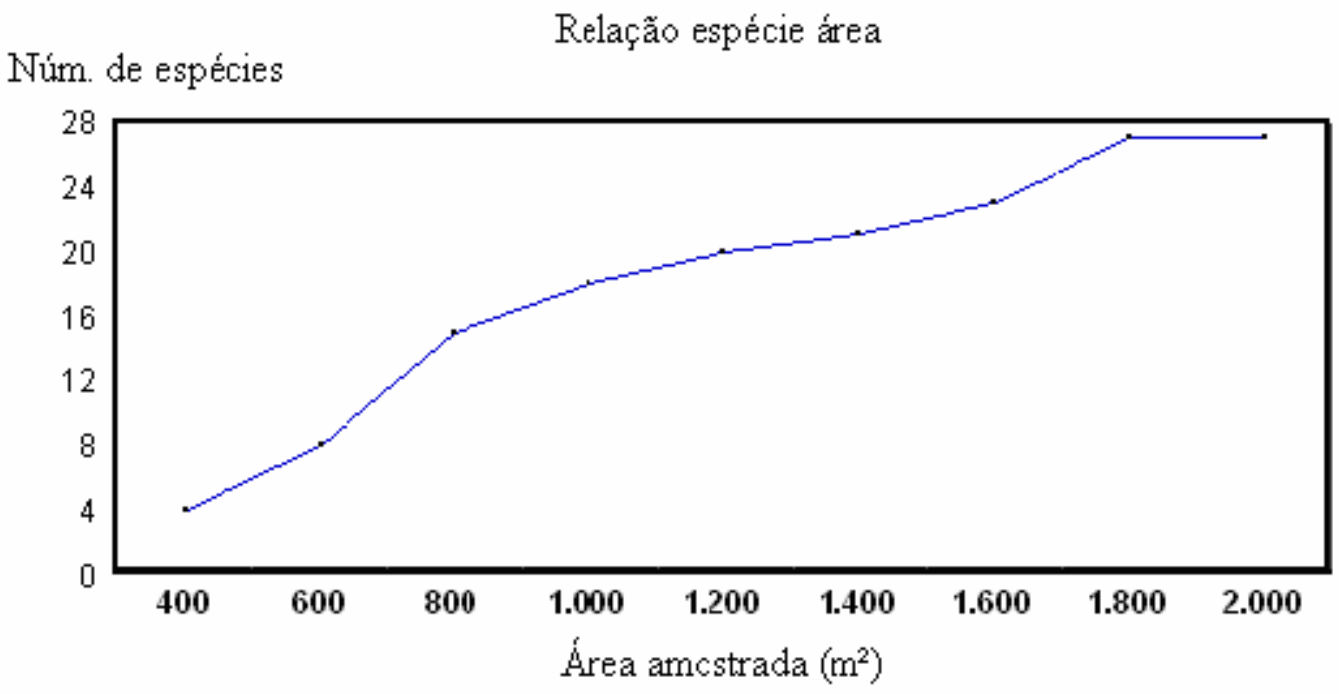

FIGURA 1: Curva espécie área na amostragem utilizada para a vegetação arbórea na Reserva Capão de Tupanciretã, Tupanciretã (RS), 2006.

FIGURE 1: Species-area curve in the sampling used for tree vegetation in Capão de Tupanciretã Reservation, Tupanciretã (RS), 2006.

Na área em estudo, amostraram-se 27 espécies no componente arbóreo da floresta, distribuídas em 24 gêneros e 18 famílias botânicas (Tabela 1).

A família com o maior número de indivíduos foi a Lauraceae com quatro espécies diferentes, seguida da família Myrtaceae e Sapindaceae com três espécies cada uma.

Farias et al. (1994), avaliando a estrutura fitossociológica de uma floresta Estacional Decidual na região de Santa Maria (RS), também encontraram-se essas três famílias como as mais importantes da floresta, além da família Meliaceae.

Comparando com trabalhos realizados por Longhi et al. (2000) e por Hack et al. (2005), em florestas da Depressão Central pertencente à Floresta Estacional Decidual, houve uma baixa diversidade de espécies no presente estudo. Essa baixa diversidade pode estar relacionada com a região de localização da floresta, pertencente ao Planalto, que é uma região de predominância de campos.

A vegetação, nessa região, ainda se encontra num estado transitório, em que os campos ainda dominam a fisionomia e vegetam num clima florestal moderado, até que as matas ao longo dos cursos de água tenham tempo para estender-se sobre a área se a intervenção humana não impedir (LINDMAN e FERRI, 1974). 
TABELA 1: Relação das espécies arbóreas amostrados na Reserva Capão de Tupanciretã, Tupanciretã (RS), 2006.

TABLE 1: Relation of the trees species samples in Capão de Tupanciretã Reservation, Tupanciretã (RS), 2006.

\begin{tabular}{lll}
\hline Família & Nome científico & Nome vulgar \\
\hline Boraginaceae & Cordia americana (L.) Gottdchiling \& J. E. Mill. & Guajuvira \\
Celastraceae & Maytenus aquifolia Mart. & Cancorosa-arbórea \\
Euphorbiaceae & Sebastiania commersoniana (Baill.) L. B. Sm. \& Downs & Branquilho \\
Fabaceae & Albizia niopoides (Spruce ex Benth.) Burkart & Angico-branco \\
Fabaceae & Enterolobium contortisiliquum (Vell.) Morong & Timbaúva \\
Laminaceae & Vitex megapotamica (Spreng.) Moldenke & Tarumã \\
Lauraceae & Nectandra lanceolata Nees & Canela-amarela \\
Lauraceae & Nectandra megapotamica (Spreng.) Mez & Canela-preta \\
Lauraceae & Ocotea puberula (Rich.) Nees & Canela-guaicá \\
Lauraceae & Ocotea pulchella (Nees) Mez & Canela-lajeana \\
Malvaceae & Luehea divaricata. Mart. \& Zucc. & Açoita-cavalo \\
Meliaceae & Melia azedarach L. & Cinamomo \\
Myrtaceae & Campomanesia guazumifolia (Cambess.) O. Berg & Sete-capotes \\
Myrtaceae & Campomanesia xanthocarpa O. Berg & Guabiroba \\
Myrtaceae & Eugenia uniflora L. & Pitangueira \\
Pittosporaceae & Pittosporum undulatum Vent. & Pitosporum \\
Rhamnaceae & Hovenia dulcis Thunb. & Uva-do-japão \\
Rubiaceae & Chomelia obtusa Cham. \& Schltdl. & Viuvinha \\
Rutaceae & Zanthoxylum rhoifolium Lam. & Mamica-de-cadela \\
Salicaceae & Banara tomentosa Clos & Guaçatunga-branca \\
Salicaceae & Casearia sylvestris Sw. & Chá-de-bugre \\
Sapindaceae & Allophylus edulis (A. St.-Hil. Cambess \& A. Juss.) Radlk. & Chal-chal \\
Sapindaceae & Cupania vernalis Cambess. & Camboatá-vermelho \\
Sapindaceae & Matayba elaeagnoides Radlk. & Camboatá-branco \\
Solanaceae & Brunfelsia australis Benth. & Primavera \\
Styracaceae & Styrax leprosus Hook. \& Arn. & Carne-de-vaca \\
Verbenaceae & Citharexylum montevidense (Spreng.) Moldenke & Tarumã-de-espinho \\
\hline & &
\end{tabular}

Na estrutura horizontal da floresta, pode-se observar a importância e ocupação das espécies pelo Valor de Importância (VI), que permite uma visão ou caracterização de cada espécie no conglomerado total da floresta. A espécie que apresentou o maior valor de importância foi Cupania vernalis, com 82,49 (Tabela 2), indicando ser a espécie com indivíduos de maiores dimensões diamétricas, representados pelo elevado valor de área basal.

O maior Valor de Cobertura (VC), índice que caracteriza uma espécie pelo número de árvores e suas dimensões, foi obtido também por Cupania vernalis, com 67,57, seguido por Sebastiania commersoniana, com 25,19. Essas duas espécies também apresentaram os maiores índices de Densidade Absoluta e Relativa, com 320 indivíduos por hectare.

Cupania vernalis também apresentou os maiores índices de Dominância e Freqüência, com 100\% de freqüência, indicando estar presente em toda a composição da floresta.

Sebastiania commersoniana foi uma das espécies que apresentou o maior número de indivíduos (235 indivíduos/ha) perdendo apenas para Cupania vernalis. Sebastiania commersoniana foi encontrada por Rondon Neto et al (2002) como a segunda espécie de maior destaque em número de indivíduos por hectare em uma Floresta Ombrofila Mista Montana em Criúva (RS), com 53,80 indivíduos por hectare.

Em trabalho realizado por Hack et al. (2005) com o objetivo de caracterizar a diversidade de espécies em um fragmento de Floresta Estacional Decidual no município de Jaguari (RS), a espécie com o maior número de indivíduos foi Cupania vernalis com 62 indivíduos de 592 amostrados na floresta. Segundo 
o autor, além do maior número de indivíduos, Cupania vernalis também obteve os maiores índices de Densidade, Dominância, Freqüência, Valor de Importância e Valor de cobertura, juntamente com Cordia americana.

TABELA 2: Parâmetros fitossociológicos das espécies amostradas no componente arbóreo da Reserva Capão de Tupanciretã, Tupanciretã (RS), 2006.

TABLE 2: Phytossociological parameters of the species samples in the tree component of Capão de Tupanciretã Reservation, Tupanciretã (Rio Grande do Sul), 2006.

\begin{tabular}{|c|c|c|c|c|c|c|c|c|c|}
\hline Nome científico & $\mathrm{N}$ & DA & DR & DoA & DoR & FA & FR & VI & $\mathrm{VC}$ \\
\hline Albizia niopoides & 1 & 5 & 0,45 & 0,0393 & 0,08 & 10 & 1,49 & 2,02 & 0,53 \\
\hline Allophylus edulis & 7 & 35 & 3,12 & 0,1382 & 0,29 & 10 & 1,49 & 4,90 & 3,41 \\
\hline Banara tomentosa & 4 & 20 & 1,78 & 0,2255 & 0,47 & 10 & 1,49 & 3,75 & 2,25 \\
\hline Brunfelsia australis & 3 & 15 & 1,34 & 0,0432 & 0,09 & 20 & 2,98 & 4,41 & 1,43 \\
\hline Campomanesia guazumifolia & 8 & 40 & 3,57 & 1,3770 & 2,86 & 40 & 5,97 & 12,41 & 6,44 \\
\hline Campomanesia xanthocarpa & 3 & 15 & 1,34 & 1,1715 & 2,44 & 30 & 4,48 & 8,25 & 3,78 \\
\hline Casearia sylvestris & 11 & 55 & 4,91 & 0,6456 & 1,34 & 50 & 7,46 & 13,72 & 6,25 \\
\hline Chomelia obtusa & 2 & 10 & 0,89 & 0,0830 & 0,17 & 20 & 2,98 & 4,05 & 1,06 \\
\hline Citharexylum montevidense & 1 & 5 & 0,45 & 0,7603 & 1,58 & 10 & 1,49 & 3,52 & 2,03 \\
\hline Cupania vernalis & 64 & 320 & 28,57 & 18,7370 & 38,99 & 100 & 14,92 & 82,49 & 67,57 \\
\hline Enterolobium contortisiliquum & 1 & 5 & 0,45 & 2,3102 & 4,80 & 10 & 1,49 & 6,75 & 5,25 \\
\hline Eugenia uniflora & 3 & 15 & 1,34 & 0,0878 & 0,18 & 10 & 1,49 & 3,01 & 1,52 \\
\hline Hovenia dulcis & 7 & 35 & 3,12 & 0,7098 & 1,48 & 50 & 7,46 & 12,06 & 4,60 \\
\hline Luehea divaricata. & 1 & 5 & 0,45 & 1,1879 & 2,47 & 10 & 1,49 & 4,41 & 2,92 \\
\hline Matayba elaeagnoides & 7 & 35 & 3,12 & 3,7869 & 7,88 & 40 & 5,97 & 16,97 & 11,01 \\
\hline Maytenus aquifolia & 10 & 50 & 4,46 & 0,4436 & 0,92 & 20 & 2,98 & 8,37 & 5,39 \\
\hline Melia azedarach. & 1 & 5 & 0,44 & 0,9817 & 2,04 & 10 & 1,49 & 3,98 & 2,49 \\
\hline Nectandra lanceolata & 11 & 55 & 4,91 & 2,3345 & 4,86 & 30 & 4,48 & 14,25 & 9,77 \\
\hline Nectandra megapotamica & 2 & 10 & 0,89 & 0,4587 & 0,95 & 20 & 2,98 & 4,83 & 1,85 \\
\hline Ocotea puberula & 7 & 35 & 3,12 & 5,3517 & 11,14 & 20 & 2,98 & 17,25 & 14,26 \\
\hline Ocotea pulchella & 10 & 50 & 4,46 & 0,4084 & 0,85 & 30 & 4,48 & 9,79 & 5,31 \\
\hline Cordia americana & 6 & 30 & 2,68 & 0,2173 & 0,45 & 20 & 2,98 & 6,11 & 3,13 \\
\hline Pittosporum undulatum & 4 & 20 & 1,78 & 0,1163 & 0,24 & 10 & 1,49 & 3,52 & 2,03 \\
\hline Sebastiania commersoniana & 47 & 235 & 20,98 & 2,0222 & 4,21 & 60 & 8,95 & 34,15 & 25,19 \\
\hline Styrax leprosus & 1 & 5 & 0,45 & 0,0098 & 0,02 & 10 & 1,49 & 1,96 & 0,47 \\
\hline Vitex megapotamica & 1 & 5 & 0,45 & 4,3874 & 9,13 & 10 & 1,49 & 11,07 & 9,58 \\
\hline Zanthoxylum rhoifolium & 1 & 5 & 0,45 & 0,0119 & 0,02 & 10 & 1,49 & 1,96 & 0,47 \\
\hline Total & 224 & 1.120 & 100,00 & 48,0466 & 100,00 & 670 & 100,00 & 300,00 & 200,00 \\
\hline
\end{tabular}

O grande número de indivíduos de Cupania vernalis amostrados na floresta pode estar relacionado com a grande produtividade de sementes viáveis pela espécie, além de ampla dispersão pela avifauna (LORENZI, 2002).

Matayba elaeagnoides também apresentou um valor de importância elevado, com 16,97. A espécie é vastamente dispersa em todas as regiões do Rio Grande do Sul, sendo característica do Planalto Meridional, porém apresenta freqüência e número de indivíduos muito irregular, dependo do tipo de solo, pois prefere solos úmidos e compactos (REITZ et al., 1983).

Analisando a Tabela 2, pode-se observar que Ocotea puberula apresentou valor de importância relativamente alto, com 17,25 , além de um elevado valor de cobertura, 14,26 . Isso pode estar relacionado com as características da espécie que, segundo Carvalho (2003), é uma das espécies secundárias iniciais mais comuns no Planalto Sul-Brasileiro, presente nas fases intermediárias e avançadas de uma sucessão secundária. Segundo o autor, é uma espécie semi-heliófila que tolera sombreamento de baixa a média 
intensidade na fase juvenil, apresenta boa regeneração natural na vegetação secundária, além de ser uma espécie muito procurada pela avifauna, o que contribui para a sua dispersão natural.

Além da ampla dispersão de Ocotea puberula, os elevados índices podem estar relacionados com grandes dimensões diamétricas dos indivíduos amostrados, pois como se pode observar na Tabela 2, Ocotea puberula apresenta um menor número de indivíduos que Ocotea pulchella, no entanto os índices de dominância, valor de importância e de cobertura são mais elevados.

Casearia sylvestris obteve um elevado valor de importância, com 13,72. Essa espécie, de acordo com Reitz et al. (1983), apresenta vasta e expressiva dispersão em todo o estado do Rio Grande do Sul.

Em estudo realizado por Longhi et al. (2000), visando a caracterizar os aspectos fitossociológicos de um fragmento de Floresta Estacional Decidual em Santa Maria (RS), obteve um elevado valor de importância para Casearia sylvestris. De acordo com o autor, essa maior importância foi definida, sobretudo, em razão do número de indivíduos (densidade) e de sua distribuição na área (freqüência) e, conseqüentemente, ocorreu uma diminuição no valor de cobertura dessa espécie, pois, apesar do grande número de indivíduos, estes se apresentam com pequenos diâmetros.

É importante ressaltar também a presença de espécies exóticas, como Hovenia dulcis e Melia azedarach no interior da floresta. Melia azedarach apresentou índices relativamente baixos, porém Hovenia dulcis apresentou indicies elevados superiores a muitas espécies nativas.

Na estrutura vertical da floresta, observa-se que o Cupania vernalis foi a espécie mais importante dos estratos superior e médio, com representação de 36,67 e 43,14\% dos indivíduos respectivamente (Tabela 3).

No estrato superior da floresta, além de Cupania vernalis, houve grande representação da Ocotea puberula, com 16,7\% dos indivíduos desse estrato, seguida pela Nectandra lanceolata, com 13,3\%. Para o estrato médio houve grande representação da Sebastiania commersoniana, com 19,6\%, espécie mais representativa do estrato inferior, com 21,3\%.

De acordo com Inoue et al. (1984) Ocotea puberula é freqüentemente encontrada em florestas secundárias, capoeiras, clareiras de matas exploradas e como elemento dominante nas bordas dos capões. Ao observar a Tabela 3, pode-se notar que Ocotea puberula apresenta o segundo maior número de indivíduos no estrato superior, e em menor proporção nos estratos médios e inferiores, isso também pode justificar o alto valor de cobertura obtido, pois os indivíduos, em sua maioria, apresentam grande porte.

Nectandra lanceolata não apresentou grande variação no número de indivíduos amostrados por estrato. Segundo Marchiori (1997), a espécie não é exigente quanto ao tipo de solo e pode caracterizar-se como esciófila ou de luz difusa, o que pode favorecer sua dispersão e desenvolvimento dentro da floresta.

Casearia sylvestris é uma espécie heliófita e seletiva higrófita, que se desenvolve abundantemente no estrato médio das florestas baixas e esparsas com bastante luz. Esse hábito caracteriza a sua distribuição com relação à estrutura vertical da floresta (Tabela 3) onde a foi encontrada apenas no estrato médio e inferior. Segundo Lorenzi (2002) Casearia sylvestris é uma espécie de pequeno porte, característica e preferencial dos sub-bosques.

Sebastiania commersoniana foi a espécie mais representativa do estrato inferior, porém não foi encontrado nenhum indivíduo dessa espécie para o estrato superior, indicando que a espécie pertence ao subbosque da floresta. Segundo Carvalho (2003) é uma espécie muito comum nas orlas dos sub-bosques, em capões situados em solos úmidos e matas baixas de beira de rios e riachos.

Também cabe ressaltar que a Hovenia dulcis, espécie exótica, está presente em todos os estratos, sobretudo no estrato inferior, indicando o potencial de invasão biológica da espécie. Em trabalho realizado por Schaaf et al. (2006), estudando modificações florístico-estruturais de um remanescente de Floresta Ombrofila Mista Montana no período entre 1979 e 2000, revela uma preocupação com esse fato, pois no levantamento realizado em 1979 não foi detectado nenhum indivíduo dessa espécie, enquanto que em 2000, a espécie superou muitas espécies nativas. 
TABELA 3: Estrutura sociológica vertical da Reserva Capão de Tupanciretã, Tupanciretã (RS), 2006.

TABLE 3: Vertical sociological structure of Capão de Tupanciretã Reservation, Tupanciretã (Rio Grande do Sul), 2006.

\begin{tabular}{|c|c|c|c|c|c|c|c|c|c|}
\hline \multirow{3}{*}{ Nome científico } & \multicolumn{9}{|c|}{ Estratos Arbóreos } \\
\hline & \multicolumn{3}{|c|}{ Superior } & \multicolumn{3}{|c|}{ Médio } & \multicolumn{3}{|c|}{ Inferior } \\
\hline & $\mathrm{N}$ & \% esp. & \% estr. & $\mathrm{N}$ & \% esp. & \% estr. & $\mathrm{N}$ & \% esp. & \% estr. \\
\hline Albizia niopoides & 0 & 0,0 & 0,0 & 0 & 0,0 & 0,0 & 5 & 0,7 & 100,0 \\
\hline Allophylus edulis & 0 & 0,0 & 0,0 & 0 & 0,0 & 0,0 & 35 & 4,9 & 100,0 \\
\hline Banara tomentosa & 0 & 0,0 & 0,0 & 5 & 2,0 & 25,0 & 15 & 2,1 & 75,0 \\
\hline Brunfelsia australis & 0 & 0,0 & 0,0 & 0 & 0,0 & 0,0 & 15 & 2,1 & 100,0 \\
\hline Campomanesia guazumifolia & 5 & 3,3 & 12,5 & 15 & 5,9 & 37,5 & 20 & 2,8 & 50,0 \\
\hline Campomanesia xanthocarpa & 5 & 3,3 & 33,3 & 0 & 0,0 & 0,0 & 10 & 1,4 & 66,7 \\
\hline Casearia sylvestris & 0 & 0,0 & 0,0 & 5 & 2,0 & 9,1 & 50 & 7,0 & 90,9 \\
\hline Chomelia obtusa & 0 & 0,0 & 0,0 & 0 & 0,0 & 0,0 & 10 & 1,4 & 100,0 \\
\hline Citharexylum montevidense & 0 & 0,0 & 0,0 & 5 & 2,0 & 100,0 & 0 & 0,0 & 0,0 \\
\hline Cupania vernalis & 55 & 36,7 & 17,2 & 110 & 43,1 & 34,4 & 155 & 21,7 & 48,4 \\
\hline Enterolobium contortisiliquum & 5 & 3,3 & 100,0 & 0 & 0,0 & 0,0 & 0 & 0,0 & 0,0 \\
\hline Eugenia uniflora & 0 & 0,0 & 0,0 & 0 & 0,0 & 0,0 & 15 & 2,1 & 100,0 \\
\hline Hovenia dulcis & 5 & 3,3 & 14,3 & 10 & 3,92 & 28,6 & 20 & 2,8 & 57,1 \\
\hline Luehea divaricata. & 5 & 3,3 & 100,0 & 0 & 0,00 & 0,0 & 0 & 0,0 & 0,0 \\
\hline Matayba elaeagnoides & 10 & 6,7 & 28,6 & 5 & 2,0 & 14,3 & 20 & 2,8 & 57,1 \\
\hline Maytenus aquifolia & 0 & 0,0 & 0,00 & 0 & 0,0 & 0,0 & 50 & 7,0 & 100,0 \\
\hline Melia azedarach. & 5 & 3,3 & 100,0 & 0 & 0,0 & 0,0 & 0 & 0,0 & 0,0 \\
\hline Nectandra lanceolata & 20 & 13,3 & 36,4 & 20 & 7,8 & 36,4 & 15 & 2,1 & 27,3 \\
\hline Nectandra megapotamica & 5 & 3,3 & 50,0 & 5 & 2,0 & 50,0 & 0 & 0,0 & 0,0 \\
\hline Ocotea puberula & 25 & 16,7 & 71,4 & 5 & 2,0 & 14,3 & 5 & 0,7 & 14,3 \\
\hline Ocotea pulchella & 0 & 0,0 & 0,0 & 15 & 5,9 & 30,0 & 35 & 4,9 & 70,0 \\
\hline Cordia americana & 0 & 0,0 & 0,0 & 5 & 2,0 & 16,7 & 25 & 3,5 & 83,3 \\
\hline Pittosporum undulatum & 0 & 0,0 & 0,0 & 0 & 0,0 & 0,0 & 20 & 2,8 & 100,0 \\
\hline Sebastiania commersoniana & 0 & 0,0 & 0,0 & 50 & 19,6 & 21,3 & 185 & 25,9 & 78,72 \\
\hline Styrax leprosus & 0 & 0,0 & 0,0 & 0 & 0,0 & 0,0 & 5 & 0,7 & 100,0 \\
\hline Vitex megapotamica & 5 & 3,3 & 100,0 & 0 & 0,0 & 0,0 & 0 & 0,0 & 0,0 \\
\hline Zanthoxylum rhoifolium & 0 & 0,0 & 0,0 & 0 & 0,0 & 0,0 & 5 & 0,7 & 100,0 \\
\hline Total & 150 & 100,00 & 6663,7 & 255 & 100,00 & 417,4 & 715 & 100,00 & 1618,9 \\
\hline
\end{tabular}

Em que: $\mathrm{N}$ = número de indivíduos; \% esp. = porcentagem da espécie no estrato em relação ao total do estrato; \% estr = porcentagem dos indivíduos da espécie no estrato.

Outro fator que pode influenciar a grande dispersão de Hovenia dulcis é a facilidade de multiplicação por sementes, além de ser uma espécie bastante rústica e de rápido crescimento (LORENZI et al., 2003). Os autores também descrevem que Hovenia dulcis possui pedicelos entumescidos que são consumidos por pessoas e animais, contribuindo ainda mais para a dispersão das sementes da espécie.

Outra espécie que merece atenção, ao analisar a estrutura vertical da floresta é Allophylus edulis, sendo encontrados indivíduos dessa espécie apenas no estrato inferior da floresta. Esse fato pode ser justificado por Reitz et al. (1983) que descreve a ocorrência da espécie no estrato médio das florestas do Rio Grande do Sul. O autor também descreve que a espécie ocorre, preferencialmente, em florestas esparsas e baixas, desenvolve-se melhor em solos úmidos de planícies e início de encostas, bem como em solos rochosos das matas mais abertas, é também bastante freqüente em capoeiras e capoeirões, e matas ciliares, apresentando-se, às vezes, distribuição irregular.

Barddal et al. (2004), estudando a fitossociologia do sub-bosque de uma Floresta Ombrófila Mista Aluvial, no município de Araucária (PR), encontraram, no sub-bosque, o maior valor de importância para Allophylus edulis, em conseqüência da sua alta densidade. Destacando-se, assim, a capacidade da espécie habitar o sub-bosque. 
Eugenia uniflora foi amostrada também apenas no estrato inferior da floresta. Isso ocorreu, provavelmente, por esta ser uma espécie de pequeno a médio porte, medindo de três a 12 metros (MARCHIORI e SOBRAL, 1997).

Cupania vernalis e Nectandra lanceolata são as espécies bem representadas nos diferentes estratos da floresta, possuindo, com isso, permanência assegurada na dinâmica da floresta.

A amostragem do componente arbustivo e da regeneração natural da floresta revelou algumas espécies que não estavam presentes na amostragem do componente arbóreo, como o Angico-vermelho (Parapiptadenia rigida (Benth.) Brenan), Capororoca (Myrsine sp.) e Capororocão (Myrsine umbellata Mart.) (Tabela 4).

TABELA 4: Representação das espécies na regeneração e no componente arbustivo da Reserva Capão de Tupanciretã, Tupanciretã (RS), 2006.

TABLE 4: Representation of the species in the regeneration and bush component of Capão de Tupanciretã Reservation, Tupanciretã (Rio Grande do Sul), 2006.

\begin{tabular}{|c|c|c|c|c|c|c|}
\hline \multirow[t]{2}{*}{ Nome científico } & \multirow[t]{2}{*}{ Nome vulgar } & \multicolumn{2}{|c|}{ Regeneração } & \multicolumn{2}{|c|}{$\begin{array}{l}\text { Vegetação } \\
\text { arbustiva }\end{array}$} & \multirow{2}{*}{$\begin{array}{c}\text { Total } \\
\mathrm{N}\end{array}$} \\
\hline & & $\mathrm{N}$ & $\%$ & $\mathrm{~N}$ & $\%$ & \\
\hline $\begin{array}{l}\text { Allophylus edulis (A. St.-Hil. Cambess. \& A. Juss.) } \\
\text { Radlk. }\end{array}$ & Chal-chal & 08 & 8,42 & 8 & 10,26 & 16 \\
\hline Brunfelsia australis Benth. & Primavera & 12 & 12,63 & 5 & 6,41 & 17 \\
\hline Campomanesia guazumifolia (Cambess.) O. Berg & Sete-capotes & 01 & 1,05 & 2 & 2,56 & 03 \\
\hline Casearia sylvestris Sw. & Carvalinho & 02 & 2,10 & 4 & 5,13 & 06 \\
\hline Chomelia obtusa Cham. et Schltdl. & Viuvinha & 02 & 2,10 & - & - & 02 \\
\hline Cupania vernalis Cambess. & $\begin{array}{l}\text { Camboatá- } \\
\text { vermelho }\end{array}$ & 32 & 33,68 & 40 & 51,28 & 72 \\
\hline Eugenia uniflora L. & Pitangueira & 05 & 5,26 & 4 & 5,13 & 09 \\
\hline Hovenia dulcis Thunb. & Uva-do-japão & 01 & 1,05 & 2 & 2,56 & 03 \\
\hline Matayba elaeagnoides Radlk. & Camboatá-branco & 06 & 6,32 & 1 & 1,28 & 07 \\
\hline Myrsine sp. & Capororoca & 01 & 1,05 & - & - & 01 \\
\hline Myrsine umbellata Mart. & Capororocão & 02 & 2,10 & - & - & 02 \\
\hline Nectandra lanceolata Nees & Canela-amarela & 05 & 5,26 & 5 & 6,41 & 10 \\
\hline Ocotea puberula (Rich.) Nees & Canela-guaicá & 07 & 7,37 & 1 & 1,28 & 08 \\
\hline Ocotea pulchella (Nees) Mez & Canela-lajeana & 04 & 4,21 & - & - & 04 \\
\hline Ocotea sp. & Canela & 01 & 1,05 & - & - & 01 \\
\hline Parapiptadenia rigida (Benth.) Brenan & Angico-vermelho & 06 & 6,32 & 1 & 1,28 & 07 \\
\hline Cordia americana L. & Guajuvira & - & - & 2 & 2,56 & 02 \\
\hline $\begin{array}{l}\text { Sebastiania commersoniana (Baill.) L. B. Sm. } \\
\text { Downs }\end{array}$ & Branquilho & & - & 3 & 3,85 & 03 \\
\hline
\end{tabular}

Em que: $\mathrm{N}$ = número de indivíduos e \% = percentual de representação da espécie no estrato.

Como se pode observar na Tabela 4, a espécie que apresentou o maior número de indivíduos em regeneração foi Cupania vernalis com 32 indivíduos, e quarenta no componente arbustivo.

O elevado número de indivíduos de Cupania vernalis na regeneração natural da floresta deve-se a grande quantidade de indivíduos adultos e grande produção de sementes dessa espécie, bem como pela alta capacidade de regeneração.

Brunfelsia australis também apresentou elevado número de indivíduos amostrados no componente arbustivo e regeneração natural, perdendo apenas para Cupania vernalis e Allophylus edulis. Esse grande número de indivíduos deve-se à adaptação da espécie a sobreviver sob sombreamento, pois é uma espécie característica de sub-bosque.

As outras espécies que apresentaram significativo número de indivíduos na regeneração natural foram: Allophylus edulis, Eugenia uniflora, Ocotea puberula, Nectandra lanceolata, Matayba elaeagnoides, Casearia sylvestris e Parapiptadenia rigida. Todas essas espécies produzem anualmente uma grande 
quantidade de sementes viáveis, o que contribui para a regeneração natural destas na floresta.

Em relação à Parapiptadenia rigida, é uma espécie pioneira a secundária inicial caracterizada como uma espécie agressiva, comum em terrenos abandonados e freqüentemente observada nas associações secundárias, ocupando posição importante nas capoeiras e nos capoeirões (CARVALHO, 2003). O autor também descreve que a espécie apresenta regeneração natural abundante em clareiras abertas na floresta e sob povoamentos instalados.

O elevado número de indivíduos de Parapiptadenia rigida na regeneração natural, apesar de ser uma espécie exigente quanto a luz também pode estar relacionada com a produção anual de grande quantidade de sementes dispersas pelo vento (INOUE et al., 1984).

Eugenia uniflora apresenta expressiva dispersão pelo Planalto do Rio Grande do Sul, muito abundante em capões situados em solos úmidos e matas de galeria. Produz anualmente uma grande quantidade de frutos apreciados pelo homem e pelos pássaros, o que contribui para a dispersão das sementes (REITZ et al., 1983).

De acordo com os resultados das espécies encontradas na regeneração natural, pode-se observar que nem todas as espécies que compõem os estratos arbóreos da floresta são encontradas na regeneração natural. Segundo Longhi et al. (2000), muitas espécies ocorrem na regeneração, porque apresentam características de permanecerem no estrato inferior, ou que pelas características próprias, não chegarão ao estrato superior da floresta. Além disso, segundo o autor, muitas espécies dos estratos superiores não são encontradas na regeneração por meio das suas exigências de luz para germinar, estabelecer-se e desenvolver-se.

Segundo Longhi (1991) a regeneração natural é um parâmetro da estrutura vertical da floresta de grande importância, pois constitui o apoio ecológico que garante a sobrevivência das espécies.

\section{CONCLUSÕES}

Pelas resultados pode-se concluir que:

As famílias mais representativas da floresta foram Lauraceae, Myrtaceae e Sapindaceae.

As espécies com maior valor de importância no componente arbóreo foram Camboatá-vermelho (Cupania vernalis Cambess.) e o Branquilho (Sebastiania commersoniana (Baill.) L. B. Sm. \& Downs).

No componente arbustivo e na regeneração, as espécies com o maior número de indivíduos foram Camboatá-vermelho (Cupania vernalis Cambess.), Primavera (Brunfelsia australis Benth., Chal-chal (Allophylus edulis (A. St-Hil., Cambess. \& A. Juss.) Radlk.), Canela-amarela (Nectandra lanceolata Nees). natural.

O “capão” estudado, típico de regiões campestres encontra-se em adiantado estágio de sucessão

A área estudada também revelou a existência de espécies exóticas, como Hovenia dulcis uma das maiores invasoras das florestas nativas.

\section{REFERÊNCIAS BIBLIOGRÁFICAS}

ANGIOSPERM PHYLOGENY GROUP II. An update of the Angiosperm Phylogeny Group classification for the orders and families of flowering plants: APG II. Botanical Journal of the Linnaean Society, [S. 1.], v. 141, n. 4, p. 399-436, 2003.

ARAÚJO, M. M. Vegetação e mecanismos de regeneração em fragmento de Floresta Estacional Decidual Ripária, Cachoeira do Sul, RS, Brasil. 2002. 153 f. Tese (Doutorado em Ciencias Florestais) - Universidade Federal de Santa Maria, Santa Maria, 2002.

BARDDAL, M. L.; RODERJAN, C. V.; GALVÃO, F.; CURCIO, G. R. Fitossociologia do sub-bosque de uma Floresta Ombrófila Mista Aluvial, no município de Araucária, PR. Ciência Florestal, Santa Maria, v. 14, n. 1, p. 35 - 45, 2004.

CALIL, F. N. Aspectos da ciclagem de nutrientes em um sistema silvipastoril com Acacia mearnsii de Wild., no município de Tupanciretã, RS. 2003. 77f. Dissertação (Mestrado em Ciências Florestais) - Universidade Federal de Santa Maria, Santa Maria, 2003.

CARVALHO, P. E. R. Espécies arbóreas brasileiras. Colombo: Embrapa, 2003. 1039 p. (Informação Tecnológica, v. 1).

CARVALHO JUNIOR, L. A.; BRENA, D. A.; LONGHI, S. J.; ARAÚJO, M. M. Fitoanálise - versão 4.0. Santa 
Maria: UFSM, 1999. soft.

CAMPOS, J. C. de; LANDGRAF, P. R. C. Análise da regeneração natural de espécies florestais em matas ciliares de acordo com a distância da margem do lago. Ciência Florestal, Santa Maria, v. 11, n. 2, p. 143-151, 2001.

FARIAS, J. A. C.; TEIXEIRA, I. F.; PES, L.; ALVAREZ FILHO, A. Estrutura fitossociológica de uma Floresta Estacional Decidual na Região de Santa Maria, RS. Ciência Florestal, Santa Maria, v.4, n.1, p. 109-128, 1994.

HACK, C.; LONGHI, S. J.; BOLIGON, A. A.; MURARI, A. B.; PAULESKI, D. T. Analise fitossociológica de um fragmento de Floresta Estacional Decidual no município de Jaguari, RS. Ciência Rural, Santa Maria, v. 35, n. 5, p. 1083 - 1091, 2005.

INOUE, M. T.; RODERJAN, C. V.; KUNIYOSHI, Y. S. Projeto Madeira do Paraná. Curitiba: FUPEF, 1984. 260 p.

LINDMAN, C. A. M.; FERRI, M. G. A vegetação no Rio Grande do Sul. São Paulo: Ed. da Universidade Federal de São Paulo, 1974. 377 p.

LONGHI, S. J. Aspectos fitossociológicos dos “capões” na região de Carovi e Tupantuba, em Santiago, RS. Ciência Florestal, Santa Maria, v. 1, n. 1, p. 22-39, 1991

LONGHI, S. J. Agrupamento e análise fitossociológica de comunidades florestais na sub-bacia hidrográfica do Rio Passo Fundo - RS. 1997. 198 p. Tese (Doutorado em Ciências Florestais) - Universidade Federal do Paraná, Curitiba, 1997.

LONGHI, S. J.; ARAÚJO, M. M.; KELling, M. B.; HOPPE, J. M.; MÜLLER, I.; BORSOI G. A. Aspectos fitossociológicos de fragmento de floresta estacional decidual, Santa Maria, RS. Ciência Florestal, Santa Maria, v. 10, n. 2, p. 59-74, 2000.

LORENZI, H. Árvores Brasileiras. Nova Odessa: Instituto Plantarum, 2002. 193 p.

LORENZI, H.; SOUZA, H. M. de; TORRES, M. A. V.; BACHER, L. B. Árvores exóticas do Brasil: madeireiras, ornamentais e aromáticas. Nova Odessa: Instituto Plantarum, 2003. 368 p.

MARCHIORI, J. N. C. Dendrologia das Angiospermas: das Magnoliáceas às Flacurtiáceas. Santa Maria: Editora da UFSM, 1997. $271 \mathrm{p}$.

MARCHIORI, J. N. C.; SOBRAL, M. Dendrologia das Angiospermas: Myrtales. Santa Maria: Ed. da UFSM, 1997. $304 \mathrm{p}$.

MARTINS. F. R. Estrutura de uma floresta mesófila. Campinas: Unicamp, 1991. 246 p.

MORENO, J. A. Clima do Rio Grande do Sul. Porto Alegre: Secretaria da Agricultura, 1961.73 p.

OLIVEIRA, A. N. de; AMARAL, I. L. do. Florística e fitossociologia de uma floresta de vertente na Amazônia Central, Amazonas, Brasil. Acta Amazônica, Manaus, v. 34, n. 1, p. 21-34, 2004.

PIRATININGA. Consultoria para monitoramento ambiental em microbacias: microbacia Ribeirão Água da Faca, 2004. Disponível em: <http://www.cati.sp.gov.br/novacati/microbacias/documentos/fauna_flora $>$. Acesso em: 08 nov. 2006.

RAMBO, B. A fisionomia do Rio Grande do Sul. Porto Alegre: Ed. da Unisinos, 1956. 473 p.

REITZ, R.; KLEIN, R. M.; REIS, A. Projeto madeira do Rio Grande do Sul. Itajaí: Herbário Barbosa Rodrigues, 1983. $525 \mathrm{p}$.

RIO GRANDE DO SUL. Governo do Estado. Secretaria Estadual do Meio Ambiente. Inventário florestal contínuo do Rio Grande do Sul. Porto Alegre: FATEC/SEMA, 2002. Disponível em: <www.ufsm.br/ifcrs.> Acesso em: 11 nov. 2006.

RONDON NETO, R. M.; WATZLAWICK, L. F.; CALDEIRA, M. V. W.; SCHOENINGER, E. R. Análise florística e estrutural de um fragmento de Floresta Ombrófila Mista Montana, situado em Criúva, RS - Brasil. Ciência Florestal, Santa Maria, v. 12, n. 1, p. 29-37 29, 2002.

SILVA JÚNIOR, M. C. da. Fitossociologia e estrutura diamétrica na mata de galeria do Pitoco, na Reserva Ecológica do IBGE, DF. Cerne, Lavras, v. 11, n. 2, p. 147-158, 2005.

SCHAAF, L. B.; FIGUEIREDO FILHO, A.; GALVÃO, F.; SANQUETTA, C. R.; LONGHI, S. J. Modificações florístico-estruturais de um remanescente de Floresta Ombrófila Mista Montana no período entre 1979 e 2000. Ciência Florestal, Santa Maria, v. 16, n. 3, p. 271-291, 2006.

STRECK, E. V. et al. Atualização da classificação taxonômica das unidades de mapeamento de levantamento de reconhecimento dos solos do Estado do Rio Grande do Sul. Porto Alegre: EMATER, 1999. 